\title{
Analisis Nilai Tambah Pengolahan Terong menjadi Keripik Terong di Desa Sriwangi Kecamatan Semendawai Suku III Kabupaten OKU Timur
}

\author{
Munsiarum \\ Sekolah Tinggi Ilmu Pertanian Belitang \\ Jln.Kampus Pertanian No.3 Belitang Kab.OKU Timur Prov.Sumatera Selatan. \\ Email : Munsiarumatmo77@gmail.com
}

\begin{abstract}
Abstrak
Tujuan dari penelitian ini adalah untuk: 1) menghitung besarnya pendapatan usaha pembuatan keripik terong di Desa Sriwangi Kecamatan Semendawai Suku III Kabupaten OKU Timur, 2) menghitung besarnya nilai tambah dalam usaha pembuatan keripik terong di Desa Sriwangi Kecamatan Semendawai Suku III Kabupaten OKU Timur, 3) menganalisis kelayakan finansial usaha pembuatan keripik terong di Desa Sriwangi Kecamatan Semendawai Suku III Kabupaten OKU Timur. Hasil penelitian menunjukkan bahwa total rata-rata pendapatan yang diperoleh usaha pengolahan keripik terong di Desa Sriwangi dalam satu kali proses produksi adalah sebesar Rp. 326.693/proses. Rata-rata besarnya nilai tambah usaha pengolahan keripik terong di Desa Sriwangi dalam satu kali proses produksi adalah sebesar Rp 20.108/Kg. Usaha pengolahan keripik terong di Desa Sriwangi layak secara finansial dengan nilai NPV Rp125.660.932, IRR 32,826\% dan Net B/C 1,88.
\end{abstract}

Kata Kunci : Value-Added, Budidaya Terong, Agroindustri.

\section{PENDAHULUAN}

\section{A. Latar Belakang}

Tanaman terong merupakan tanaman asli daerah tropis yang diduga berasal dari Asia terutama di India dan Burma. Terong dapat tumbuh dengan baik pada ketinggian hingga 1.200 meter di atas permukaan laut. Tanaman terong yang dipelihara dengan baik, akan mampu mencapai tingkat produksi yang berkisar 4-5 $\mathrm{Kg} /$ pohon. Sehingga pada lahan seluas 1 hektar akan mampu menghasilkan terong sebanyak \pm 90 ton. Dari kawasan tersebut, terong kemudian disebarkan ke China pada abad ke-5, selanjutnya disebarluaskan ke Karibia, Afrika Tengah, Afrika Timur, Afrika Barat, Amerika Selatan dan daerah-daerah tropis lainnya. Terong disebarkan pula ke negara-negara subtropis, seperti Spanyol dan negara lain di kawasan Eropa.. Terong merupakan salah satu jenis sayuran buah yang digemari berbagai kalangan. Terong merupakan komoditas yang cukup banyak beredar di pasaran namun tidak dipungkiri bahwa sifat mudah rusak dari terong yang sangat ditakuti oleh para pedagang, terong juga bisa dikonsumsi secara langsung maupun secara tidak langsung atau melalui proses pengolahan (Astawan, 2009).

Mengingat prospek komoditi terong yang cukup besar, maka perlu disusun program pengembangan buah terong antara lain dengan mengolah buah terong menjadi kripik terong sebuah produk yang banyak diminati masyarakat. Alasan utama penggunaan buah terong adalah selain buah terong disukai karena rasanya yang enak, aroma yang khas dan mengandung vitamin yang baik untuk kesehatan. Terong mengandung komposisi mineral dan vitamin yang cukup lengkap meskipun dalam jumlah rendah seperti vitamin B-kompleks, Thiamin, Pyridoxine, Ribiflafin, Zat Besi, Phosphorus, Manganese dan Potassium.
Kandungan Fosfor pada terong sama dengan yang terkandung dalam wortel $(37 \mathrm{mg} / 100 \mathrm{mg}$ ) (Haryoto, 2009).

Terong merupakan salah satu hasil pertanian Indonesia yang jumlahnya cukup melimpah, terong ini oleh masyarakat sering dijadikan bahan untuk pembuatan makanan, salah satu olahan makanan yang menggunakan terong sebagai bahan utamanya yaitu keripik terong. Dengan dibuatnya olahan keripik terong ini dapat meningkatkan nilai jual dari terong itu sendiri. Nama olahan keripik terong ini sudah tidak asing lagi bagi masyarakat, dimana olahan makanan ini banyak disukai oleh masyarakat mulai dari kalangan anak-anak hingga kalangan dewasa. Tingginya pecinta olahan keripik terong inilah yang bisa dijadikan kekuatan bisnis keripik terong. Maka dengan menjaga agar kualitas dan komuditas hasil pertanian (terong) tetap perlu adanya pengolahan pemanfaatan hasil pertanian yang lebih luas dan kaya akan ide-ide atau gagasan baru, salah satunya yaitu dengan mengolahnya menjadi produk makanan ringan. Keripik terong adalah olahan berbahan dasar terong dan tepung (tepung beras, tepung terigu, tepung bumbu,), garam, ketumbar, dan bawang putih. Keripik terong umumnya dimatangkan dengan digoreng dan dipanggang di dalam oven supaya keripik renyah dan tahan lama.

Pengolahan terong menjadi keripik terong awalnya responden melihat banyaknya petani terong yang ada di sekitar sehingga muncullah ide yang digunakan responden untuk menciptakan inovasi produk makanan ringan sebagai oleh-oleh khas Belitang karena belum adanya produk tersebut di pasaran sekitaran OKU Timur. Selain itu, bisa menjadikan lapangan pekerjaan bagi ibu-ibu rumah tangga dan membantu meningkatkan pendapatan rumah tangga. Responden lalu melakukan inovasi tersebut dengan mengolah terong menjadi keripik terong dan 
memanfaatkan bahan baku yang tersedia secara melimpah di sekitarnya. Jenis terong yang digunakan yaitu terong ungu dan hijau panjang yang masih muda karena terong tersebut memiliki tekstur lebih getas dibanding dengan terong jenis lainnya. Responden membuat olahan keripik terong dengan dua varian rasa yaitu rasa original dan rasa balado. Respoden mendapatkan bahan baku dari petani terong yang ada di Desa Sriwangi dengan harga $\mathrm{Rp}$ 3000/Kg dan responden menjual keripik terong dengan harga $\mathrm{Rp}$ 20.000/bungkus rasa original, $\mathrm{Rp} 25.000 /$ bungkus rasa balado dengan berat 400 gram/bungkus. Pemasaran yang dilakukan responden yaitu dengan memasukkan produk keripik terong di mini market (212 mart), warung-warung dan pasar tradisional. Promosi yang dilakukan responden yaitu secara langsung dengan masyarakat dan melalui media sosial (online).

Tujuan pengolahan terong menjadi keripik terong adalah memberikan nilai tambah dan meningkatkan kemanfaatan terong tersebut. Keripik terong dibuat dengan proses digoreng terlebih dahulu lalu dipanggang di dalam oven untuk mendapatkan kerenyahan yang maksimal, untuk bahan bakunya tersedia banyak di Desa Sriwangi dan sekitarnya.

\section{B. Rumusan Masalah}

Adapun rumusan dalam penelitian adalah :

1. Berapa besar pendapatan usaha pembuatan keripik terong di Desa Sriwangi Kecamatan Semendawai Suku III Kabupaten OKU Timur?

2. Berapa besar nilai tambah yang diperoleh dari usaha pembuatan keripik terong di Desa Sriwangi Kecamatan Semendawai Suku III Kabupaten OKU Timur?

3. Bagaimana analisis kelayakan finansial usaha pembuatan keripik terong di Desa Sriwangi Kecamatan Semendawai Suku III Kabupaten OKU Timur?

\section{Tujuan dan Kegunaan Penelitian}

Adapun tujuan dari penelitian ini adalah:

1. Untuk menghitung besarnya pendapatan usaha pembuatan keripik terong di Desa Sriwangi Kecamatan Semendawai Suku III Kabupaten OKU Timur.

2. Untuk menghitung besarnya nilai tambah dalam usaha pembuatan keripik terong di Desa Sriwangi Kecamatan Semendawai Suku III Kabupaten OKU Timur.

3. Untuk menganalisis kelayakan finansial usaha pembuatan keripik terong di Desa Sriwangi Kecamatan Semendawai Suku III Kabupaten OKU Timur.

Kegunaan dari penelitian ini adalah :

1. Sebagai bahan informasi dan referensi dalam mengembangkan ilmu pengetahun bagi penulis, khususnya kegiatan home industri pengolahan keripik terong.
2. Sebagai bahan informasi dan referensi bagi peneliti selanjutnya yang terkait dengan penelitian ini.

\section{Hipotesis}

Hipotesis dari rumusan masalah dapat dikemukakan

1. Bahwa biaya produksi pengolahan terong menjadi keripik terong lebih kecil dari pada penerimaan sehingga akan diperoleh pendapatan.

2. Bahwa pengolahan terong menjadi keripik terong mempunyai nilai tambah.

3. Bahwa pengolahan terong menjadi keripik terong layak secara finansial.

\section{KERANGKA TEORITIS}

\section{A. Tinjauan Pustaka}

\section{B. Model Pendekatan}

Model pendekatan yang digunakan dalam penelitian ini adalah model pendekatan secara diagramatis yaitu sebagai berikut :

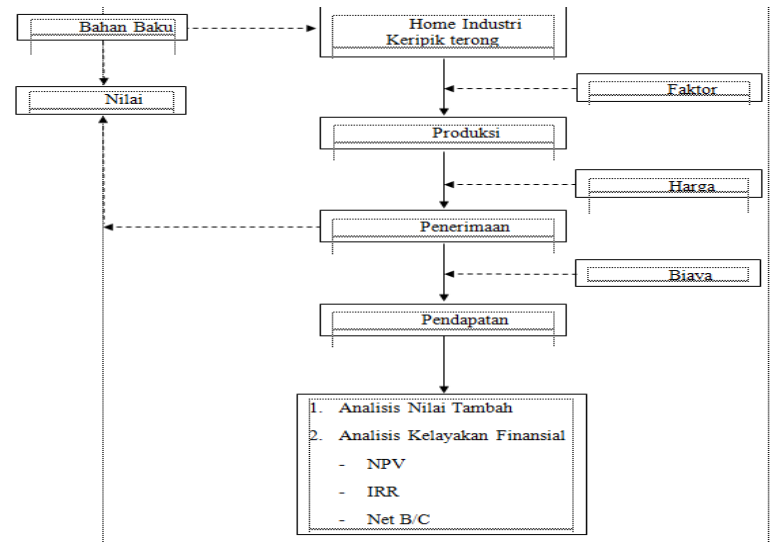

Keterangan :

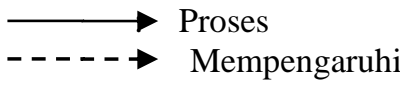

\section{Pembatasan Masalah}

1. Responden adalah pelaku home industri keripik terong yang berada di Desa Sriwangi Kecamatan Semendawai Suku III Kabupaten OKU Timur.

2. Terong adalah tumbuhan penghasil buah yang dijadikan sayur-sayuran, yang menjadi bahan baku utama keripik terong.

3. Keripik terong adalah jenis makanan yang berbentuk cemilan renyah yang diproses dengan penggorengan dan oven dengan bahan baku terong dan bahan tambahan lainnya.

4. Biaya tetap adalah biaya yang penggunaannya tidak habis dalam sekali proses produksi dan besar kecilnya tidak mempengaruhi jumlah produksi (Rp/PP). 
5. Biaya variabel adalah biaya yang jumlahnya tergantung dari besarnya jumlah produksi serta habis dalam satu kali proses produksi (Rp/PP).

6. Biaya produksi adalah total biaya yang dikeluarkan dalam satu kali proses produksi yang meliputi biaya tetap dan biaya variabel (Rp/PP).

7. Produksi adalah produk yang dihasilkan oleh responden berupa keripik terong dengan satuan (Bungkus).

8. Harga adalah nilai jual dari keripik terong yang ditetapkan oleh responden pada saat penelitian (Rp/Bungkus).

9. Penerimaan adalah jumlah dari hasil produksi (Kg/PP), yang diperoleh home industri dikali dengan harga $(\mathrm{Rp} / \mathrm{Kg})$, pada saat penelitian (Rp/PP).

10. Pendapatan adalah selisih antara penerimaan dengan biaya produksi yang dikeluarkan selama proses produksi berlangsung.

11. Bahan baku yang digunakan adalah terong yang berwarna ungu dengan bentuk lonjong.

12. Nilai tambah adalah selisih antara output yang dihasilkan dengan biaya antara bahan baku ( $\mathrm{Rp} / \mathrm{Kg})$.

13. Kelayakan usaha adalah penelitian atau analisa terhadap suatu usaha agribisnis pembuatan usaha pengolahan terong menjadi keripik terong layak dan dapat diusahakan/dikembangakan, dihitung dengan rumus NPV, IRR, dan Net B/C.

\section{METODE PENELITIAN}

\section{A. Tempat dan Waktu}

Penelitian ini telah dilaksanakan di Desa Sriwangi Kecamatan Semendawai Suku III Kabupaten OKU Timur. Penentuan lokasi dilakukan secara sengaja dengan pertimbangan bahwa di Desa Sriwangi terdapat industri rumah tangga pengolahan terong menjadi keripik terong. Sedangkan penelitian telah dilaksanakan pada Bulan Maret 2020.

\section{B. Metode Penelitian dan Pengambilan sampel}

Metode yang digunakan dalam penelitian adalah studi kasus. Menurut Walgito (2010), studi kasus merupakan suatu metode untuk menyelidiki atau mempelajari suatu kejadian mengenai perseorangan atau suatu usaha. Sample dalam penelitian ini yaitu home industri yang berada di Desa Sriwangi Kecamatan Semendawai Suku III Kabupaten OKU Timur. Sedangkan metode penarikan contoh dengan menggunakan metode sensus terhadap satu orang responden yaitu Ibu Noni yang mengusahakan home industri pengolahan terong menjadi keripik terong di Desa Sriwangi Kecamatan Semendawai Suku III Kabupaten OKU Timur.

\section{Metode Pengumpulan Data}

Metode pengumpulan data dilakukan yaitu dengan cara observasi langsung yang dilakukan dengan cara pengambilan data primer dan data sekunder :
1. Pengambilan data primer adalah data yang diperoleh dengan melakukan pengamatan secara langsung ke lokasi penelitian serta wawancara langsung menggunakan daftar pertanyaan (quisioner) kepada pelaku usaha pengolahan terong menjadi keripik terong di Desa Sriwangi Kecamatan Semendawai Suku III Kabupaten OKU Timur.

2. Pengambilan data sekunder diperoleh dari lembaga-lembaga yang tekait meliputi keadaan umum wilayah penelitian, data yang berasal dari buku perpustakaan maupun internet.

\section{Metode Pengolahan Data}

Data yang diperoleh dari lapangan dianalisa secara deskriptif serta diolah menggunakan analisis matematis.

1. Untuk menjawab tujuan yang pertama yaitu untuk menghitung besarnya pendapatan usaha pembuatan keripik terong menggunakan rumus:

a. Untuk mengetahui biaya produksi digunakan rumus (Soekartawi, 2016) :

$\mathrm{TC}=\mathrm{VC}+\mathrm{FC}$

Dimana :

$\mathrm{TC}=$ Total Cost $/$ Total Biaya Produksi (Rp)

$\mathrm{FC}=$ Fixed Cost/Biaya Tetap (Rp)

$\mathrm{VC}=$ Variable Cost/Biaya Tidak tetap $(\mathrm{Rp})$

b. Untuk mengetahui besarnya penerimaan digunakan rumus (Soekartawi, 2016)

$\mathrm{TR}_{\mathrm{i}}=\mathrm{Y}_{\mathbf{i}} \times \mathrm{Py} \mathbf{i}$

Dimana :

$\mathrm{TR}_{\mathrm{i}}=$ Total Revenue/ Total Penerimaan $(\mathrm{Rp})$

$\mathrm{Y}_{\mathrm{i}}=$ Yeild $/$ Produksi yang diperoleh dalam suatu usaha tani $(\mathrm{Kg} /$ proses $)$

$\mathrm{Py}_{\mathrm{i}}=$ Price yield/ Harga jual $(\mathrm{Rp} / \mathrm{Kg})$

c. Untuk menghitung pendapatan digunakan rumus (Soekartawi, 2016):

$\mathrm{Pd}=\mathrm{TR}-\mathrm{TC}$

Dimana :

$\mathrm{Pd}=$ Pendapatan Usahatani $(\mathrm{Rp})$

$\mathrm{TR}=$ Total Revenue $/$ Penerimaan $(\mathrm{Rp})$

$\mathrm{TC}=$ Total Cost/Total Biaya $(\mathrm{Rp})$

2. Untuk menjawab tujuan yang ke dua yaitu untuk menghitung nilai tambah digunakan analisis (Yudi, 2010) :

AV $\quad=$ TR - IC

Dimana :

$\mathrm{AV}=$ Added Value/Nilai Tambah

$\mathrm{TR}=$ Total Revenue/total penerimaan

IC =Intermediate cost/ Biaya Antara ( kecuali tenaga kerja keluarga)

3. Untuk menjawab tujuan ketiga (kelayakan usaha) dengan menggunakan analisis finansial (NPV,IRR dan Net B/C).

a. Pendekatan untuk mengetahui Net Present Value ( NPV) nilai kini bersih (Ibrahim, 2009)

$N P V=\sum_{i=1}^{n} N B_{i}(1+i)^{-n}$

Keterangan:

NPV $=$ Net Present Value 


$$
\begin{array}{ll}
\mathrm{NB} & =\text { Net Benefit }=\text { Benefit }- \text { Cost } \\
\mathrm{C} & =\text { Cost }(\text { Total Biaya) } \\
\mathrm{i} & =\text { Discount factor (tingkat suku bunga) } \\
\mathrm{n} & =\text { tahun (waktu ) }
\end{array}
$$

b. Internal Rate of Return (IRR) laju

keberhasilan usaha (Ibrahim, 2009)

$$
\begin{aligned}
& \mathrm{IRR}=\mathrm{i} 1+ \\
& \frac{\mathrm{NPV} 1}{(N P V 1-N P V 2)} X(i 2-i 1)
\end{aligned}
$$
NPV1 = NPV pada tingkat discount rate terendah ( positif)
NPV2 = NPV pada tingkat discount rate tertinggi ( negative )
i2 = Tingkat discount rate yang menghasilkan NPV1
i2 = Tingkat discount rate yang menghasilkan NPV2

Jika IRR > SOCC maka proyek dikatakan layak

IRR = SOCC berarti proyek pada BEP

IRR < SOCC dikatakan bahwa proyek tidak layak.

c. Untuk mengetahui tingkat kelayakan pedapatan agribisnis dengan rumus Net B/C ( Ibrahim, 2009 )

$$
N e t B / C=\frac{\sum_{i=1}^{n} N \overline{B_{i}}(+)}{\sum_{i=1}^{n} N \overline{B_{i}}(-)}
$$

Dengan keretria

Net $\mathrm{B} / \mathrm{C}>1$ berarti usaha tersebut layak dikembangkan.

Net $\mathrm{B} / \mathrm{C}=1$ berarti usaha tidak untung tidak rugi (impas).

Net $\mathrm{B} / \mathrm{C}<1$ berarti usaha tidak menguntungkan (rugi).

\section{HASIL DAN PEMBAHASAN}

\section{A. Analisis Biaya Usaha Pengolahan Keripik Terong}

Dari hasil penelitian yang telah dilakukan dari responden yang berada di Desa Sriwangi telah diperoleh data-data primer yang akan peneliti olah secara tabulasi dan matematis. Biaya dalam kegiatan usaha dikeluarkan oleh pengusaha dengan tujuan untuk menghasilkan pendapatan yang tinggi bagi suatu usaha yang dikerjakan, dengan mengeluarkan biaya maka pengusaha mengharapkan pendapatan yang setinggi-tingginya melalui peningkatan produksi. Biaya dalam kegiatan usaha pengolahan keripik terong terdiri dari biaya tetap (fixed cost) dan biaya variabel (variable cost).

\section{Biaya Tetap (Fixed Cost)}

Biaya yang digunakan dan dikeluarkan oleh responden usaha pengolahan keripik terong di Desa Sriwangi diantaranya meliputi biaya sewa lahan dan biaya penyusutan peralatan yang dapat dilihat pada tabel 1 sebagai berikut :
Tabel 1. Rata-rata Biaya Tetap Usaha Pengolahan Keripik Terong di Desa Sriwangi.

\begin{tabular}{cccc}
\hline \multirow{2}{*}{ No } & Uraian & \multicolumn{2}{c}{ Nilai } \\
& & $(\mathbf{R p} /$ Proses $)$ & $(\mathbf{R p} / \mathbf{B} / n)$ \\
\hline 1 & Sewa Tempat & 8.333 & 250.000 \\
2 & Penggunaan Alat & 4.928 & 73.927 \\
\hline & Total Biaya Tetap & 13.262 & 323.927 \\
\hline
\end{tabular}

Sumber : Olahan Data Primer,2020.

Berdasarkan tabel diatas dapat diketahui bahwa biaya sewa tempat pengolahan keripik terong adalah sebesar Rp 8.333/proses, atau Rp 250.000/Bulan. Biaya penggunaan alat adalah sebesar $\mathrm{Rp}$ 13.262/proses, dan Rp 323.927/Bulan. Jadi rata-rata biaya tetap yang dikeluarkan dalam usaha pengolahan keripik terong sebesar Rp 13.262 /proses, dan Rp 323.927 /Bulan.

\section{Biaya Variabel (Variable Cost)}

Biaya variabel yang digunakan dalam usaha pembuatan keripik terong terdiri atas biaya pembelian bahan baku dan biaya tenaga kerja. Bahan baku yang digunakan dalam pembuatan keripik terong yaitu terong, tepung beras, tepung terigu, tepung krispy, garam, ketumbar, minyak goreng dan bawang putih yang diperoleh dari pasar Desa Sriwangi. Besarnya biaya variabel yang dikeluarkan respoden pengolahan keripik terong dapat dilihat pada tabel berikut.

Tabel 2. Total Rata-rata Biaya Variabel Pengolahan Keripik Terong di Desa Sriwangi.

\begin{tabular}{cccc}
\hline \multirow{2}{*}{ No } & Uraian & \multicolumn{2}{c}{ Nilai } \\
& & (Rp/Proses) & (Rp/Bulan) \\
\hline 1 & Biaya Bahan Baku & 986.045 & 29.581 .363 \\
2 & Biaya Tenaga Kerja & 300.000 & 9.000 .000 \\
\hline & Total Biaya Variabel & $\mathbf{1 . 2 8 6 . 0 4 5}$ & $\mathbf{3 8 . 5 8 1 . 3 6 3}$ \\
\hline
\end{tabular}

Sumber : Olahan Data Primer,2020.

Berdasarkan hasil pada tabel diatas dapat diketahui bahwa biaya bahan baku pengolahan keripik terong dalam satu kali proses produksi sebesar Rp 986.045 /proses atau sebesar Rp 29.581.363/bulan. Besarnya biaya tenaga kerja adalah $\mathrm{Rp}$ 300.000/proses atau sebesar Rp 9.000.000/bulan. Jadi total biaya variabel $\mathrm{Rp} 1.286 .045 /$ proses atau $\mathrm{Rp}$ 38.581.363/bulan.

\section{Biaya Produksi}

Biaya total dalam usaha pengolahan keripik terong terdiri dari biaya tetap ditambah biaya variabel. Besarnya biaya total yang dikeluarkan responden pengolahan keripik terong dapat dilihat tebel berikut ini : 
Tabel 3. Total Rata-rata Biaya Produksi Pengolahan Keripik Terong di Desa Sriwangi.

\begin{tabular}{lccc}
\hline \multirow{2}{*}{ No } & Uraian & Nilai & \multicolumn{2}{c}{ (Rp/Proses) } & (Rp/Bulan) \\
\hline \multirow{2}{*}{1} & Biaya Tetap & 13.262 & 323.927 \\
2 & Biaya Variabel & 1.286 .045 & 38.581 .363 \\
\hline & & $\mathbf{1 . 2 9 9 . 3 0 7}$ & $\mathbf{3 8 . 9 0 5 . 2 9 0}$ \\
\hline
\end{tabular}

Sumber : Olahan Data Primer,2020.

Berdasarkan hasil pada tabel diatas, dapat diketahui bahwa biaya tetap pengolahan keripik terong adalah Rp 13.262/proses atau Rp 323.927/bulan. Biaya variabel sebesar $\mathrm{Rp}$ 1.286.045/proses atau Rp 38.581.363/bulan. Jadi biaya total produksi pengolahan keripik terong adalah Rp 1.299.307/proses atau Rp 38.905.290/bulan.

\section{B. Produksi, Harga, Penerimaan dan Pendapatan}

Hasil akhir atau produksi dalam usaha pengolahan keripik terong adalah berupakeripik/makanan ringan. Penerimaan merupakan produk yang diterima dari pengolahan keripik terong yang dikalikan dengan harga sedangkan pendapatan adalah selisih dari penerimaan dengan biaya produksi. Produksi, harga penerimaan dan pendapatan dapat dilihat pada tabel berikut ini :

Tabel 4. Rata-rata Produksi, Harga, Penerimaan dan Pendapatan Pengolahan Keripik Terong di Desa Sriwangi.

\begin{tabular}{|c|c|c|c|}
\hline No & Uraian & Satuan & Nilai \\
\hline \multirow[t]{3}{*}{1} & Produksi & & \\
\hline & 400 gram & Bungkus/Proses & 75 \\
\hline & 200 gram & Bungkus/Proses & 9 \\
\hline \multirow[t]{3}{*}{2} & Harga & & \\
\hline & Rp20.000 & Rp/Bungkus & 1.513 .333 \\
\hline & Rp13.000 & Rp/Bungkus & 112.667 \\
\hline 3 & Penerimaan & Rp/Proses & 1.626 .000 \\
\hline 4 & Biaya total produksi & Rp/Proses & 1.299 .307 \\
\hline 5 & Pendapatan & Rp/Proses & 326.693 \\
\hline
\end{tabular}

Sumber : Olahan Data Primer,2020.

Berdasarkan pada tabel diatas, dapat dilihat bahwa dalam satu kali proses produksi keripik terong 400 gram adalah 75 bungkus dan 200 gram adalah 9 bungkus. Rata-rata harga jual adalah sebesar Rp 20.000/bungkus dan Rp 13.000/bungkus sehingga dihasilkan rata-rata penerimaan adalah $\mathrm{Rp}$ 1.626.000/proses. Rata-rata total biaya produksi adalah Rp 1.299.307/sehingga diperoleh pendapatan Rp 326.693/proses.

\section{Analisis Nilai Tambah Pengolahan Jamu instan}

Analisis nilai tambah pengolahan keripik terong di Desa Sriwangi dapat dilihat pada tabel sebagai berikut Tabel 5. Rata-rata Nilai Tambah Pengolahan keripik terong di Desa Sriwangi.

\begin{tabular}{rlrl}
\hline No & \multicolumn{1}{c}{ Uraian } & \multicolumn{1}{c}{ Nilai } & Satuan \\
\hline 1 & Kebutuhan Terong & 25 & $\mathrm{Kg} / \mathrm{PP}$ \\
2 & Biaya Produksi & 1.299 .307 & $\mathrm{Rp} / \mathrm{PP}$ \\
3 & Penerimaan & 1.626 .000 & $\mathrm{Rp} / \mathrm{PP}$ \\
4 & Pendapatan & 326.693 & $\mathrm{Rp} / \mathrm{PP}$ \\
5 & Biaya Antara & 1.299 .307 & $\mathrm{Rp} / \mathrm{PP}$ \\
6 & Nilai Tambah & 326.693 & $\mathrm{Rp} / \mathrm{PP}$ \\
7 & Nilai Tambah & 13.068 & $\mathrm{Rp} / \mathrm{kg}$ \\
\hline
\end{tabular}

Sumber : Olahan Data Primer,2020.

Penerimaan yang diperoleh dari produksi keripik terong dalam sekali proses produksi sebesar Rp 1.626.000/proses. Biaya antara diperoleh dari biaya total produksi dikurang dengan biaya tenaga kerja keluarga sehingga diperoleh biaya antara sebesar Rp 1.299.307/proses. Nilai tambah diperoleh dari total penerimaan Rp 1.626.000/proses dikurang biaya antara sebesar Rp 1.299.307/proses sehingga diperoleh nilai tambah sebsesar Rp 326.693/proses atau diperoleh nilai tambah sebsesar Rp 13.068/Kg.

\section{Analisis Kelayakan Usaha}

Studi kelayakan nmerupakan bahan pertimbangan mengambil suatu keputusan, menerima atau menolak suatu gagasan usaha yang direncanakan. Suatu usaha dikatakan layak kalau keuntungan yang diperoleh dapat menutup seluruh biaya yang dikeluarkan.

\section{Analisis NPV}

Net Present Value (NPV) atau nilai kini bersih adalah analisis manfaat finansial yang digunakan untuk mengukur layak tidaknya suatu usaha dilaksanakan dilihat dari nilai sekarang (present value). Kriteria dari kelayakan usaha ini adalah proyek layak jika NPV lebih besar dari satu (positif) dan sebaliknya proyek tidak layak jika NPV nilainya lebih kecil dari satu (negatif). Untuk menghitung kelayakan finansial usaha pengolahan keripik terong selama 5 tahun usaha yaitu tahun 2019 sampai dengan tahun 2020 dihitung menggunakan Compounding Factor dan tahun 2021 sampai dengan tahun 2023 dihitung menggunakan Discon Faktor.

Tabel 6. Analisis NPV Usaha Pengolahan Keripik Terong di Desa Sriwangi.

\begin{tabular}{|c|c|c|c|c|c|c|c|c|}
\hline Tahun & Biaya Investasi & Biaya Operasional & Total Biaya & Penerimaan & Pendapatan & CF $7 \%$ & Def7\% & Present Value 7\% \\
\hline 2019 (1) & 153.533 .000 & 76.792 .884 & 230.325 .884 & 97.294.000 & $(133.031 .884)$ & 1,07 & - & $(142.344 .116)$ \\
\hline $20200(0)$ & 141.000 & 509.939 .011 & 510.0800.011 & 585.424 .000 & 75.343 .989 & 1,00 & . & 75.3439899 \\
\hline 2021 (1) & 192.000 & 520.055 .700 & 520.247 .700 & 592.200 .000 & 71,952300 & & 0,93 & 67.245 .140 \\
\hline $2022(2)$ & 173.000 & 518.562800 & 518.735 .800 & 594.300 .000 & 75.564 .200 & & 0,87 & 66.000 .699 \\
\hline $2023(3)$ & 265.000 & 521.248 .800 & 521.513 .800 & 594.300 .000 & 72.786 .200 & & 0,82 & 59.415 .221 \\
\hline
\end{tabular}

Sumber : Olahan Data Primer,2020. 
Dari perhitungan NPV selama 5 tahun usaha yaitu tahun 2019 sampai tahun 2023 dengan tingkat suku bunga $7 \%$ dengan menggunakan compounding faktor dan discon faktor maka diperoleh nilai NPV adalah Rp 125.660.932. Berdasarkan hasil analisis diperoleh nilai NPV > 1, hal ini menunjukkan bahwa usaha pengolahan keripik terong di Desa Sriwangi layak secara finansial.

\section{Analisis IRR (Internal Rate of Return)}

Kriteria yang dipakai untuk menunjukkan bahwa suatu usaha layak untuk dijalankan adalah jika nilai IRR lebih besar dari tingkat suku bunga yang berlaku pada saat usaha tersebut diusahakan. Jadi jika IRR lebih tinggi dari tingkat suku bank maka usaha yang direncanakan layak secara finansial untuk dilaksanakan.

Tabel 7. Analisis IRR Usaha Pengolahan Keripik Terong di Desa Sriwangi.

\begin{tabular}{|c|c|c|c|c|c|}
\hline Tahun & Net Benfift & CFdan DF $7 \%$ & $\mathrm{NPV}$ at CF dan DF 7\% & CF dan DF $33 \%$ & $\mathrm{NPV}$ at CF dan DF $33 \%$ \\
\hline 1 & $(133.031 .884)$ & 1,07 & $(142.344 .116)$ & 1,33 & $(189.317 .674)$ \\
\hline 0 & 75.3439989 & 1.00 & 75.343 .989 & 1,00 & $75,343,989$ \\
\hline 1 & 71.9533000 & 0.93 & 67.255 .140 & 0.75 & 50.560 .256 \\
\hline 2 & 75.564 .200 & 0.87 & 66.000 .699 & 0.57 & 37.31 .718 \\
\hline 3 & 72.786 .200 & 0,82 & 59.415 .221 & 0,43 & 25.257 .734 \\
\hline & \multicolumn{2}{|r|}{$\operatorname{NPV}(+)$} & 125.600 .932 & $\operatorname{NPV}(\cdot)$ & $(846.978)$ \\
\hline
\end{tabular}

Sumber : Olahan Data Primer,2020.

$$
\begin{aligned}
& \operatorname{IRR}= \\
& \mathrm{i}_{1}+\frac{\mathrm{NPV}(+)}{\mathrm{NPV}(+)-\operatorname{NPV}(-)} \times \mathrm{i}_{2}-\mathrm{i}_{1} \\
& 7 \%+\frac{125.660 .932}{126.507 .910} \times 33 \%-7 \% \\
& 7 \%+0,993304941 \quad \times 26 \% \\
& 7 \%+\quad 25,82592845 \\
& 32,826 \%
\end{aligned}
$$

Berdasarkan perhitungan pada tabel 7 diatas diperoleh nilai NPV positif (+) adalah Rp 125.660.932 dan nilai NPV negative (-) terkecil dengan nilai interest $\left(i_{2}\right)$ sebesar $33 \%$ adalah $\mathrm{Rp}$ (846.978). Berdasarkan hasil perhitungan dengan menggunakan compounding factor dan discon faktor maka diperoleh keuntungan bersih setelah didisconto sebesar nilai $32,826 \%$ yang berarti nilai IRR lebih besar dari pada nilai tingkat suku bunga bank sebesar 7\%. Hal ini menunjukkan bahwa usaha pengolahan keripik terong di Desa Sriwangi layak (feasible) secara finansial untuk dikembangkan.

\section{Analisis Net $\mathbf{B} / \mathbf{C}$}

Net B/C adalah perbandingan antara jumlah NPV positif dengan jumlah NPV negatif dan ini menunjukkan gambaran berapa kali lipat benefit akan kita peroleh dari cost yang kita keluarkan. Suatu proyek akan dipilih apabila nilai $($ Net $B / C>1)$, sebaliknya bila suatu proyek memberikan nilai (Net $B / C<1)$, maka proyek tidak diteruskan.

Tabel 8. Analisis Net B/C Usaha Pengolahan Keripik

\begin{tabular}{cccc}
\multicolumn{4}{c}{ Terong di Desa Sriwangi. } \\
\hline Tahun & Net Benefit & CF dan DF 7\% & Present Value 7\% \\
\hline 1 & $(133.031 .884)$ & 1,07 & $(142.344 .116)$ \\
0 & 75.343 .989 & 1,00 & 75.343 .989 \\
1 & 71.952 .300 & 0,93 & 67.245 .140 \\
2 & 75.564 .200 & 0,87 & 66.000 .699 \\
3 & 72.786 .200 & 0,82 & 59.415 .221 \\
\hline
\end{tabular}

Sumber : Olahan Data Primer,2020.

$$
\begin{aligned}
\text { NetB } / C & =\frac{\sum_{i=1}^{n} N \overline{B_{i}}(+)}{\sum_{i=1}^{n} N \overline{B_{x}}(-)} \\
& =\frac{268.005 .048}{142.344 .116} \\
& =\quad 1,88
\end{aligned}
$$

Nilai Net B/C diperoleh dengan menjumlahkan nilai Net Benefit positif (+) kemudian hasilnya dibagi dengan nilai Net Benefit negatif(-). Net benefit positif adalah sebesar 268.005.048 dan nilai Net Benefit negatif sebesar -142.344.116. Berdasarkan hasil perhitungan, diperoleh nilai Net B/C 1,88 artinya setiap Rp 1 yang dikeluarkan untuk usaha pengolahan keripik terong maka akan mendapatkan pendapatan setelah didisconto sebesar Rp 1,88. Nilai Net B/C $1,88>1$ berarti usaha pengolahan keripik terong di Desa Sriwangi layak secara financial.

\section{KESIMPULAN DAN SARAN}

\section{A. Kesimpulan}

Berdasarkan hasil dan pembahasan dari penelitian yang telah dilaksanakan, maka dapat diambil kesimpulan sebagai brikut :

1. Total rata-rata pendapatan yang diperoleh usaha pengolahan keripik terong di Desa Sriwangi dalam satu kali proses produksi adalah sebesar Rp 326.693/proses.

2. Rata-rata besarnya nilai tambah usaha pengolahan keripik terong di Desa Sriwangi dalam satu kali proses produksi adalah sebesar Rp 20.108/Kg.

3. Usaha pengolahan keripik terong di Desa Sriwangi layak secara finansial dengan nilai NPV Rp125.660.932, IRR 32,826\% dan Net B/C 1,88.

\section{B. SARAN}

1. Hendaknya kehadiran home industri keripik terong dapat meningkatkan perekonomian masyarakat sekitar dan dapat menjadi motivasi bagi masyarakat serta terdaftarkan di BPOM.

2. Hendaknya produksi keripik terong tetap berlanjut meski ditengah-tengah pandemic COVID-19 tetapi harus tetap dengan protokol kesehatan.

3. Untuk pemerintah hendaknya ditingkatkan lagi dalam memberikan modal usaha agar usaha home industri keripik terong mampu meningkatkan produksinya.

\section{DAFTAR PUSTAKA}

Astawan. 2009. Terong Anti Kangker. Dinas Pertanian Jawa Tengah.

Daniel, Moehar. 2002. Pengantar Ekonomi Pertanian. Bumi Aksara. Jakarta.

Fatah, L. 2007. Dinamika Pembangunan Pertanian dan Pedesaan. Pustaka Banua. Banjarbaru.

Firdaus, M. 2009. Manajemen Agribisnis. Bumi Aksara, Jakarta.

Gumbira, Sa,id E. dan Harizt Intan. 2000. Manajemen Agribisnis. Ghalia Indonesia. Jakarta. 
Harini. 2008. Makro Ekonomi Pengantar. PT. Gramedia Pustaka Utama. Jakarta.

Haryoto. 2009. Bertanam Terung dalam pot. Kanisius. Yogyakarta.

Hongren, Charles T. 2000. Akuntansi Biaya: Dengan Penekanan Manajerial. Salemba Empat. Jakarta.

Ibrahim, Y. 2009. Study Kelayakan Bisnis. Rineka. Jakarta.

Jumingan. 2009. Studi Kelayakan Bisnis. Bumi Aksara. Jakarta.

Kastasapoetra. 2006. Manajemen Pertanian Agribisnis. PT Gramedia Jakarta

Marinih. 2005. Pembuatan Keripik Kimpul Bumbu Balado Dengan Tingkat PedasYang Berbeda. Skripsi. Jurusan Tata Boga dan Produksi. Universitas Semarang. Semarang. 